\title{
Microbial IAA: Spectral Analysis and Application to Modulate Growth of Triticum aestivum
}

\author{
Ammara Abid and Ambreen Ahmed* \\ Department of Botany, University of the Punjab, Quaid-e-Azam Campus, Lahore 54590, Pakistan
}

\section{A BSTRACT}

Plant growth promoting rhizobacteria (PGPR) play an essential part in transformation, solubilization, and mobilization of nutrients procured from the soil. Plant-microbe interaction can be termed as an eco-friendly approach which not only improves plant growth but helps in sustaining the soil and prevents environmental degradation from agrochemicals. PGPR improve plant growth through various mechanisms. One of the mechanisms involved is phytohormone production by the bacterial strains. In the current study, spectral analysis of thirteen already isolated and identified auxin-producing microbial strains (AAL1, AB8, A7B, A5C, A3E, A11E, AL2, A9G, A12G, A13G, AM10, P4, and S6) was carried out. Fourier transform infrared spectroscopy (FTIR) of the bacterial IAA exhibited close structural similarity between bacterial IAA and standard IAA. The growth-enhancing capability of strains was verified through the application of these strains on Triticum aestivum seedlings and enhancement of growth was statistically analyzed which indicated remarkable improvement in growth and metabolism both under laboratory and field conditions. Several bacterial isolates also proved to be very effective in improving biochemical parameters of plants. The current study suggested that the application of IAA-producing PGPR as biofertilizer is effective in enhancing plant growth as well as plant yield.

$\begin{array}{ll}\text { Keywords } & \text { *Address of Correspondence } \\ \text { FTIR, IAA, PGPR, Biofertilizers, Triticum } & \text { ambreenahmed1@hotmail.com } \\ \text { aestivum. } & \end{array}$

Cite this article: Abid A, Ahmed A. Microbial IAA: Spectral Analysis and Application to Modulate Growth of Triticum aestivum. RADS J. Biol. Res. Appl. Sci. 2018; 9(2): 53-63.

This is an Open Access article distributed under the terms of the Creative Commons Attribution License (http://creativecommons.org/licenses/by/4.0), which permits unrestricted use, distribution, and reproduction in any medium, provided the original work is properly cited.

\section{INTRODUCTION}

Microorganisms are too small to be seen with the naked eye i.e., app. 1 to $100 \mu \mathrm{m}$. In spite of having microscopic size, they have major contributions to the stability of the ecosystem. Microbial activities involving growth rate and metabolism take place at microscopic level but exert great impact at macroscopic level ${ }^{1}$. The aim behind the implementation of the microbial application is to increase the nutrient availability and improving the growth and development of plants which is an indispensable practice for agriculture. In the recent years, the utilization of plant growth promoting rhizobacteria (PGPR) has been multiplied tremendously in different regions of the world for the sustainable ecosystem and agriculture ${ }^{2}$. Human population is increasing day by day due to which ample farming has been practiced now-a-days, which excessively depends upon agrochemicals that lead to a great number of hazardous health and environmental issues. Hence, environment-friendly methods must be applied to retain the quality of soil and crops ${ }^{3}$. Plant growth promoting rhizobacteria (PGPR) are capable of enhancing nutrients supply in the rhizosphere and inducing the transport processes in roots 4 .

The rhizosphere is a hot spot of microbial abundance and activities due to the presence of root exudates and rhizodeposits ${ }^{5}$. The plant growth promoting rhizobacteria are generally known as nodule promoting rhizobacteria 
(NPR) or plant health promoting rhizobacteria (PHPR) with reference to the soil which is the major environment for plant-microbe interactions ${ }^{2}$. PGPR have been proven beneficial for enhancing the plant growth via direct and indirect mechanisms ${ }^{6}$. PGPR utilization as biofertilizers is an appropriate practice for producing better crops with minimal use of chemical fertilizers by stimulating different processes in plants such as mobilization of nutrients, biocontrol and phytohormone production ${ }^{7}$.

\section{MATERIALS AND METHODS}

\section{Growth of Bacterial Isolates}

Thirteen already isolated and identified auxin-producing bacterial isolates, Bacillus sp. (AAL1), Bacillus sp. (P4), Bacillus sp. (AB8), Bacillus sp. (S6), Cronobacter sp. (AL2), Enterobacter sp. (A3E), Enterobacter sp. (A5C), Enterobacter sp. (A7B), Enterobacter sp. (A11E), Enterobacter sp. (A9G), Enterobacter sp. (AM10), Enterobacter sp. (A12G) and Exiguobacterium sp. (A13G) by Ahmed $^{16}$ were used in the present study. All the bacterial strains were routinely grown at $37^{\circ} \mathrm{C}$ for 24 hours using L-Agar and L-broth 8 .

\section{Fourier Transform Infrared Spectroscopy (FTIR)}

The production of auxin by the bacterial isolates was first checked by colorimetric analysis. Auxin synthesis by the bacterial isolates was later confirmed by Fourier transform infrared spectroscopic (FTIR) analysis. Spectral analysis was carried out using Agilent Cary 630 FTIR. The bacterial strains were grown using LB-medium for 24 hours at $37{ }^{\circ} \mathrm{C}$ in the presence of tryptophan. After centrifugation of 24 hours incubated bacterial culture, the supernatant was collected and its $\mathrm{pH}$ was adjusted to 3 using $6 \mathrm{~N} \mathrm{HCl}$. Bacterial auxin was extracted from the supernatant thrice by using ethyl acetate. After the removal of ethyl acetate through vaporization, the residue was collected in methanol and was analyzed through Fourier Transform Infrared Spectroscopy. Synthetic IAA (Sigma) was used as standard and also analyzed through FTIR.

\section{Effect of Bacterial Treatment on the Growth of Triticum aestivum}

Certified seeds of Triticum aestivum var. Fd-08 were used in the current study. Healthy seeds of wheat were obtained from Organization in Lahore (Pakistan) named as Punjab Seed Corporation. Sterilization and pregermination inoculation treatments were given to the seeds following Ahmed and Hasnain ${ }^{9}$. Under laboratory conditions, pots were filled with $0.2 \mathrm{~kg}$ sieved soil, six replicates were taken for each treatment and 11 treated seedlings were transferred to each pot and placed under 10 Klux light with a photoperiod of 16 hours at $30+2^{\circ} \mathrm{C}$. Harvest was taken after 30 days of inoculation and several growth parameters like root length, shoot length, fresh weight, the number of leaves of plants, as well as biochemical parameters i.e., protein content and auxin content, were estimated.

Under field conditions, pots were filled with $7.5 \mathrm{~kg}$ sieved soil, six replicates for each treatment were taken and 15 seeds were sown per pot after treatment with bacterial cultures. After germination of the seedlings, thinning of plants was done to have 11 seedlings per pot. These wheat plants were grown in pots till maturity. Plants were then harvested and various physical parameters were studied like number of leaves, spike length, shoot length, seed weight, spikelet length, number of tillers and grain yield after 140 days of inoculation. Biochemical parameters such as protein estimation following Lowry et al. ${ }^{10}$ and auxin estimation following Mahadevan ${ }^{11}$ were performed twice, firstly, after 90 days of inoculation and secondly, after 140 days of inoculation i.e., at maturity. Both auxin and protein content was estimated using leaves of treated and non-treated plants.

\section{Statistical Analysis}

The data obtained were analyzed statistically by using the software SPSS.v.16. Duncan's multiple range test was applied for comparing means through analysis of variance.

\section{RESULTS}

Fourier Transform Infrared Spectroscopy (FTIR)

Spectral analysis of microbial IAA obtained from the selected auxin-producing isolates i.e., Bacillus sp. (AAL1), Cronobacter sp. (AL2), Bacillus sp. (P4), Bacillus sp. (S6), Bacillus sp. (AB8), Enterobacter sp. (A5C), Enterobacter sp. (A11E), Enterobacter sp. (A7B), Enterobacter sp. (A12G), Enterobacter sp. (A3E), Enterobacter sp. (A9G), Enterobacter sp. (AM10), Exiguobacterium sp. (A13G) and synthetic IAA (Sigma) as standard was carried out. The interferogram of standard IAA exhibited $-\mathrm{OH}$ peak at 
$3384 \mathrm{~cm}^{-1}$. The spectral region ranging between 2800 $3100 \mathrm{~cm}^{-1}$ showed $\mathrm{C}-\mathrm{H}$ stretching bands indicating the presence of fatty acid chains and amino acid chains, $-\mathrm{CN}$ peak is at $737 \mathrm{~cm}^{-1}$ and the aromatic ring was present ranging between $1407-1686 \mathrm{~cm}^{-1}$. The interferogram obtained from microbial IAA extracted from bacterial strains Bacillus sp. (AAL1), Bacillus sp. (P4), Enterobacter sp. (A3E), Cronobacter sp. (AL2) exhibited -OH spectral region at $3411 \mathrm{~cm}^{-1}$ and lies in the range of $2400-3400$ $\mathrm{cm}^{-1}$. The $-\mathrm{CH}$ band recorded in the spectral range of $2800-3100 \mathrm{~cm}^{-1}$, the C-N band was at $2942 \mathrm{~cm}^{-1}$ and the aromatic ring lies within 1400-1600 $\mathrm{cm}^{-1}$. The interferogram obtained from analysis of microbial IAA extracted from the bacterial isolates Bacillus sp. (S6), Bacillus sp. (AB8), Enterobacter sp. (A9G), Enterobacter sp. (A5C) and Enterobacter sp. (A7B) was also carried out and $-\mathrm{OH}$ band showed peaks between 2400-3400 $\mathrm{cm}^{1}$. The $-\mathrm{CH}$ band was present between $2800-3100 \mathrm{~cm}^{-1}$ and the aromatic ring was present between 1420-1654 $\mathrm{cm}^{-1}$. The $-\mathrm{CH}$ stretching band indicates the presence of fatty acid and amino acid which was in the range of 2800$3100 \mathrm{~cm}^{-1}$ and the $-\mathrm{CN}$ band was at $1015 \mathrm{~cm}^{-1}$. Bacterial IAA extracted from Enterobacter sp. (AM10) showed

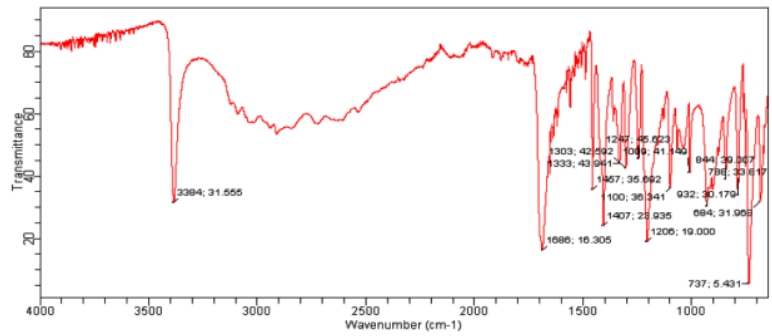

a)

Fig. 1: Interferogram obtained through FTIR analysis. (a) Standard IAA (b) Microbial IAA extracted from Enterobacter sp. (AM10).

\section{Effect of Bacterial Treatment on Growth of Triticum aestivum (30 Days Old Plants)}

In the laboratory trial, enhancement in germination percentage was shown by treatment with bacterial isolates such as Bacillus sp. (AB8) exhibited up to $14 \%$, Cronobacter sp. exhibited $16 \%$ percentage and Exiguobacterium sp. (A13G) up to $9.5 \%$ increase respectively, in comparison to control (Fig. 2). Plants inoculated with bacterial strains Cronobacter sp. (AL2), Bacillus sp. (AAL1) and Enterobacter sp. (A7B) showed similar results such as the $-\mathrm{OH}$ spectral region lies between $2400-3400 \mathrm{~cm}^{-1}$ and the stretching bands of $-\mathrm{CH}$ were present between $2800-3100 \mathrm{~cm}^{-1}$ and of $-\mathrm{OH}$ band between $2400-3400 \mathrm{~cm}^{-1}$. The aromatic group was present ranging between $1420-1670 \mathrm{~cm}^{-1}$ and $-\mathrm{CN}$ band was at $1016 \mathrm{~cm}^{-1}$ (Fig. 1).

Interferogram obtained from the bacterial strain Enterobacter sp. (A11E), Exiguobacterium sp. (A13G) and Enterobacter sp. (A12G) also showed that -OH peak lies between $2400-3400 \mathrm{~cm}^{-1}$. The aromatic band ranges between 1420-1458 $\mathrm{cm}^{-1}$. Similarly $-\mathrm{CH}$ stretching peak observed at $2833 \mathrm{~cm}^{-1}$ and $\mathrm{CN}$ peak at $1022 \mathrm{~cm}^{-1}$. Interferograms obtained through Fourier transform infrared spectroscopy (FTIR) revealed that structurally microbial IAA is similar to standard IAA as indicated from the comparable peaks in the interferograms obtained using microbial IAA [extracted from selected bacterial isolates $(A B 8, A 5 C, A A L 1, A 7 B, A 3 E, A 11 E, A 9 G, A 12 G$, AL2, AM10, A13G, P4, S6)] and standard IAA. These results were further supported by plant growth enhancement of wheat plants after bacterial treatment both under laboratory and field conditions.

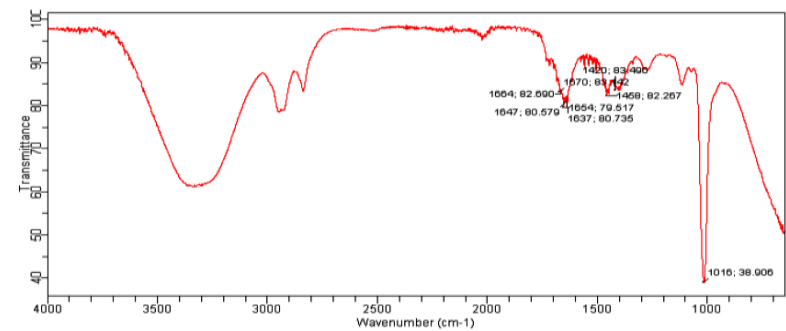

b) significant enhancement in shoot length i.e., 14, 12 and $9 \%$ respectively. Inoculation with bacterial isolate Enterobacter sp. (A7B) exhibited significant improvement in root length up to $27 \%$. Plants treated with bacterial isolates such as Exiguobacterium sp. (A13G), Enterobacter sp. (A5C) and Bacillus sp. (AB8) have also exhibited a significant increase in root length up to 19, 20 and $21 \%$ over control plants (Fig. 3). Enterobacter sp. (AL2) and Cronobacter sp. (AL2) showed improvement in the number of leaves i.e., 11 and $12 \%$ respectively, over non-inoculated plants (Fig. 4). Plants treated with the 
bacterial isolates also exhibited a significant enhancement in fresh weight over non-treated plants. Treatments with Cronobacter sp. (AL2) [28.2\%], Bacillus sp. (AAL1) [28.2\%], Bacillus sp. (S6) [33.3\%] showed a significant increase while Enterobacter sp. (A9G) showed 13\% reduction in fresh weight over control (Fig. 5). Treatment with the microbial isolates Enterobacter sp. (AM10) and Exiguobacterium sp. (A13G) exhibited a significant increase in protein content i.e., $152 \%$ and $175 \%$ over control (Fig. 7). Cronobacter sp. (AL2) exhibited 224\% significant enhancement in auxin over non-treated plants. Moreover, improvement in auxin content was recorded by the treatment with bacterial strains i.e., Bacillus sp. (P4) up to $150 \%$ and Enterobacter sp. (A7B) up to $145 \%$ compared to control. Few bacterial isolates such as AAL1, S6, A11E and A3E exhibited a decrease in auxin content over control (Fig. 8).

Effect of bacterial treatment on the growth of Triticum aestivum (90 and 140 days old plants)

Under field conditions, plants treated with bacterial strain Enterobacter sp. (A5C) showed up to $22.5 \%$ while Cronobacter sp. (AL2) showed $22.1 \%$ increase in germination percentage over non-treated plants (Fig. 2). Shoot length enhancement up to $40 \%$ was observed after the application of Enterobacter sp. (A9G) (Fig. 3). Plants inoculated with Enterobacter sp. (A5C) exhibited significant enhancement in the number of leaves up to $32 \%$ over non-inoculated plants (Fig. 4). Maximum significant improvement in tiller number was observed by Enterobacter sp. (A9G) treatment i.e. 35\% compared to control (Fig. 4). The plants inoculated with the bacterial isolate Enterobacter sp. (A3E) exhibited a maximum significant enhancement in spike length up to $15.5 \%$ while Enterobacter sp. (A5C) showed significant improvement in spikelet length up to $18.1 \%$ over control (Fig. $4 \& 5$ ). Significant improvement was observed in the grain yield of treated plants over non-treated plants. Plants inoculated with Enterobacter sp. (A9G) exhibited significant increase in grain yield up to $37.5 \%$ as compared to plants without bacterial treatment. Similarly, plants treated with the isolate Bacillus sp. (AAL1) showed maximum significant increase in seed weight i.e., $29.7 \%$ over control (Fig. 5 \& 6).

Under field conditions, protein analysis of 90 days old plants, revealed $34 \%$ protein enhancement in plants treated with Enterobacter sp. (A5C) as compared to noninoculated plants.

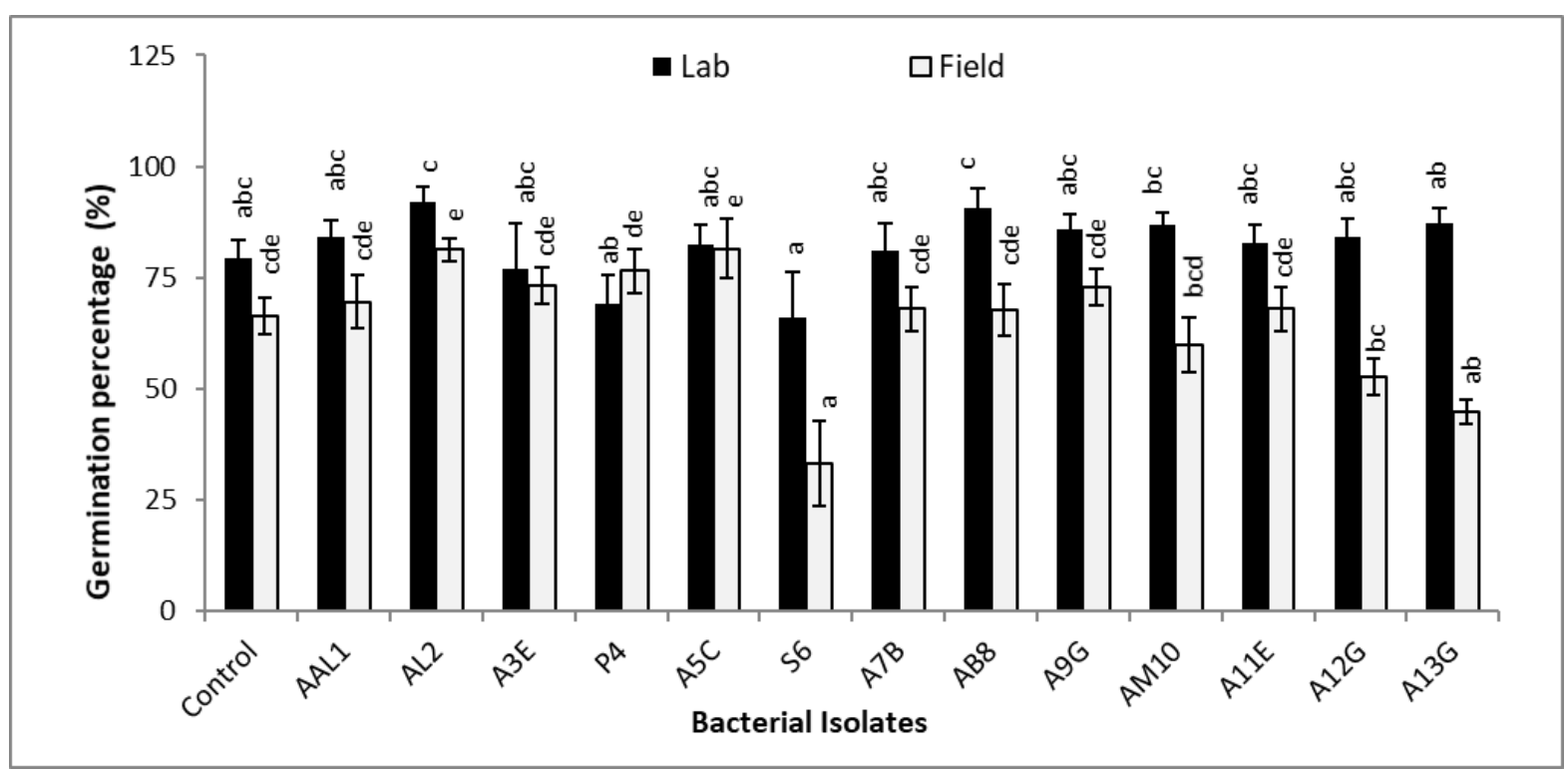

Fig. 2: Effect of bacterial inoculations on germination percentage of Triticum aestivum (Fd-08) under laboratory and field conditions. Data represent mean of sixty-six plants. Different letters represent a significant difference between treatments using Duncan's multiple range test $(\mathrm{P}=0.05)$. 


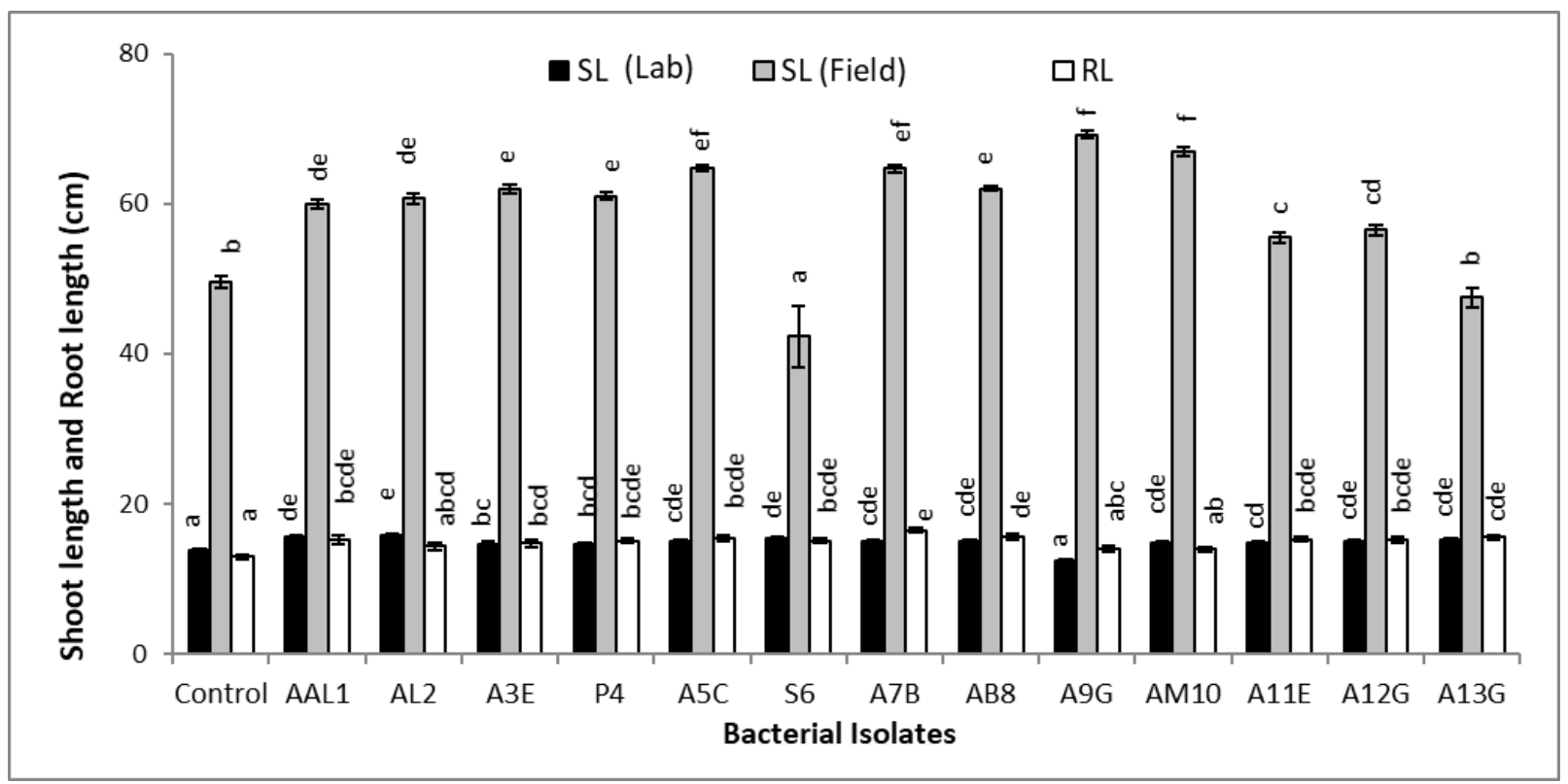

Fig. 3: Effect of bacterial inoculations on shoot length and root length of Triticum aestivum (Fd-08) under laboratory and field conditions. Data represent mean of sixty-six plants. Different letters represent a significant difference between treatments using Duncan's multiple range test $(P=0.05)$ [SL: Shoot length, RL: Root length $(\mathrm{Lab})]$.

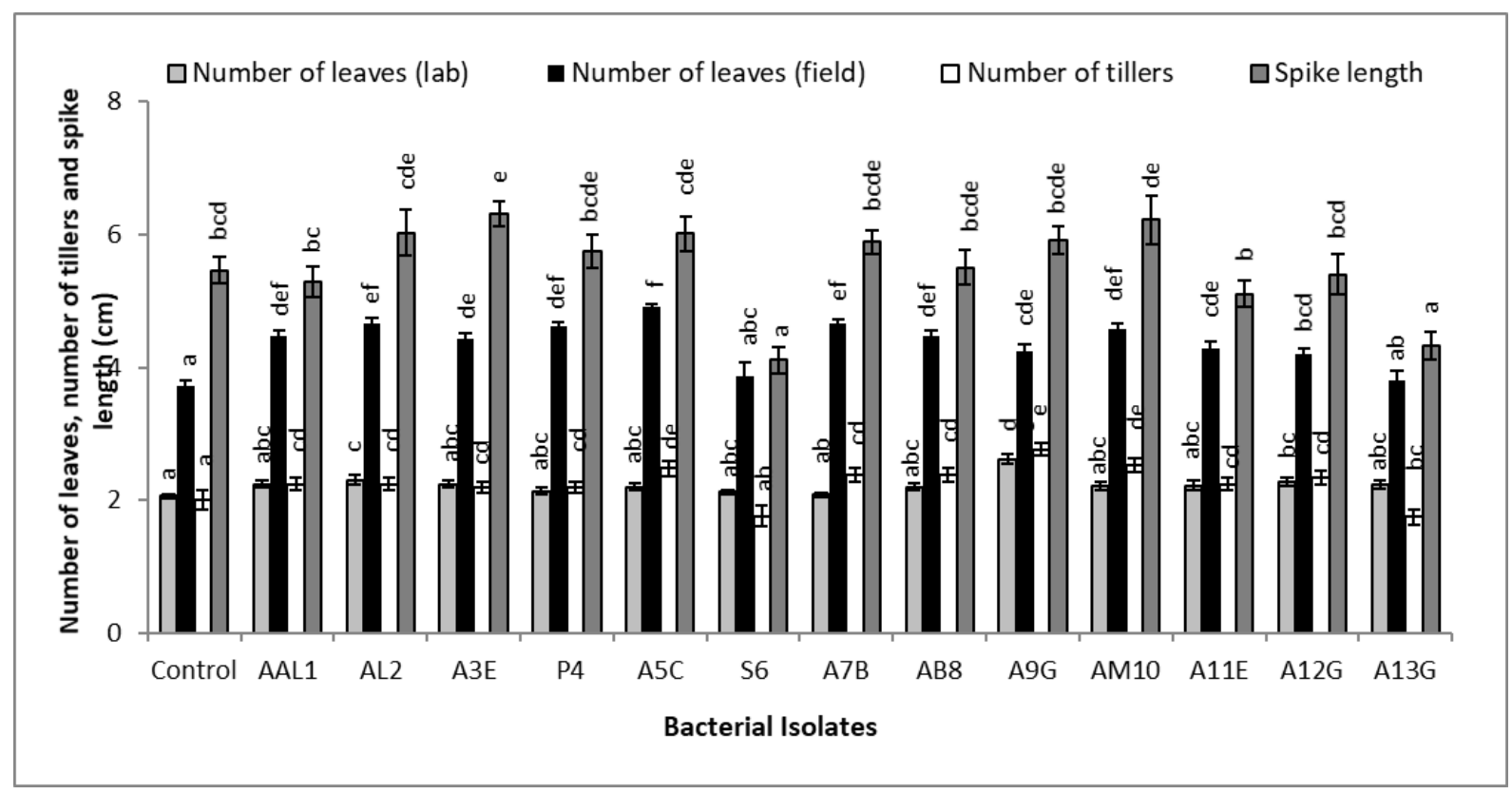

Fig. 4: Effect of bacterial inoculations on number of leaves, number of tillers, spike length $(\mathrm{cm})$ of Triticum aestivum (Fd08) under laboratory and field conditions. Data represent mean of sixty-six plants. Different letters represent a significant difference between treatments using Duncan's multiple range test $(P=0.05)$. 


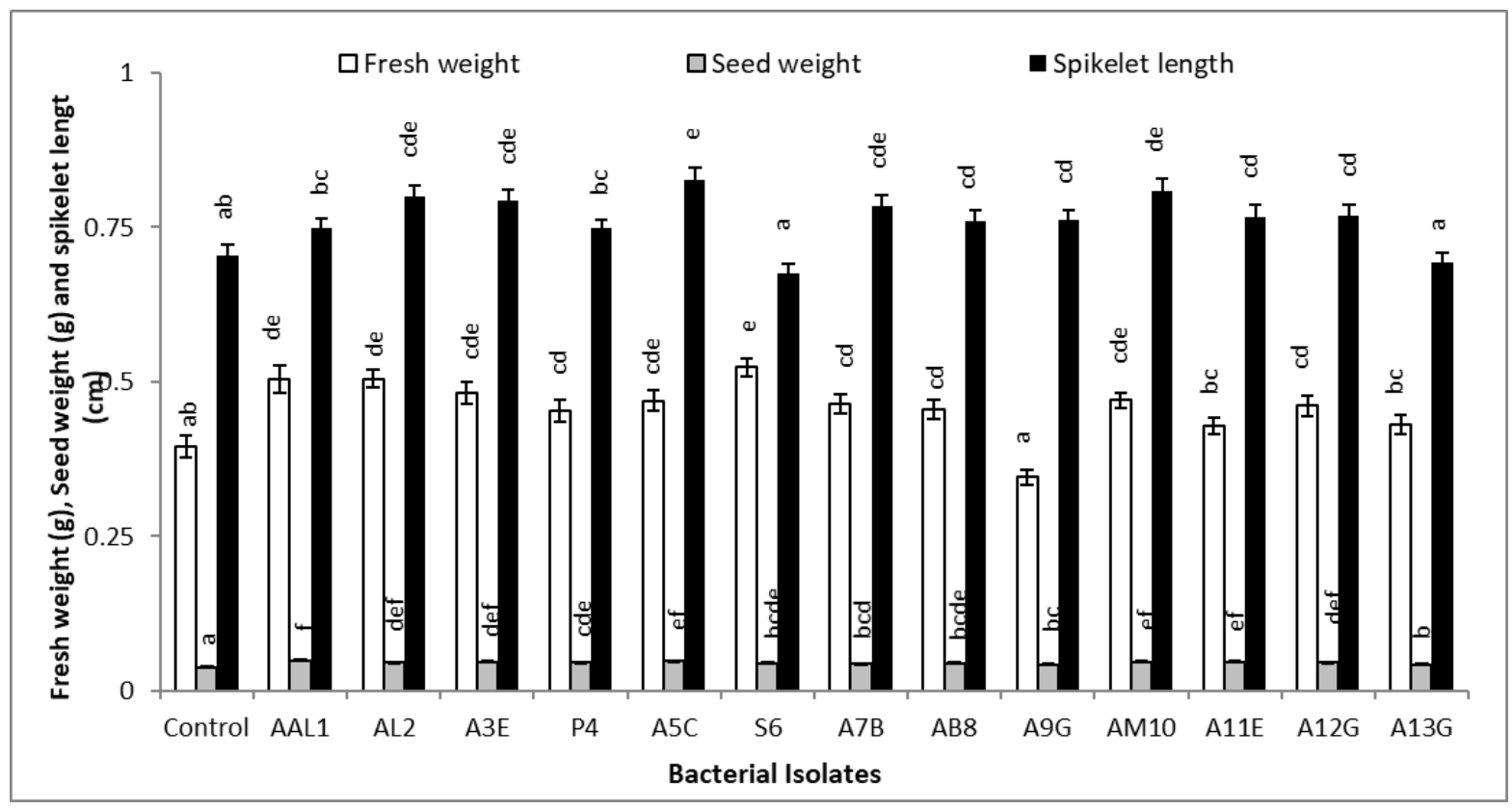

Fig. 5: Effect of bacterial inoculations on a fresh weight $(\mathrm{g})$, seed weight $(\mathrm{g})$, spikelet length $(\mathrm{cm})$ of Triticum aestivum (Fd-08) under laboratory and field conditions. Data represent mean of sixty-six plants. Different letters represent a significant difference between treatments using Duncan's multiple range test $(P=0.05)$.

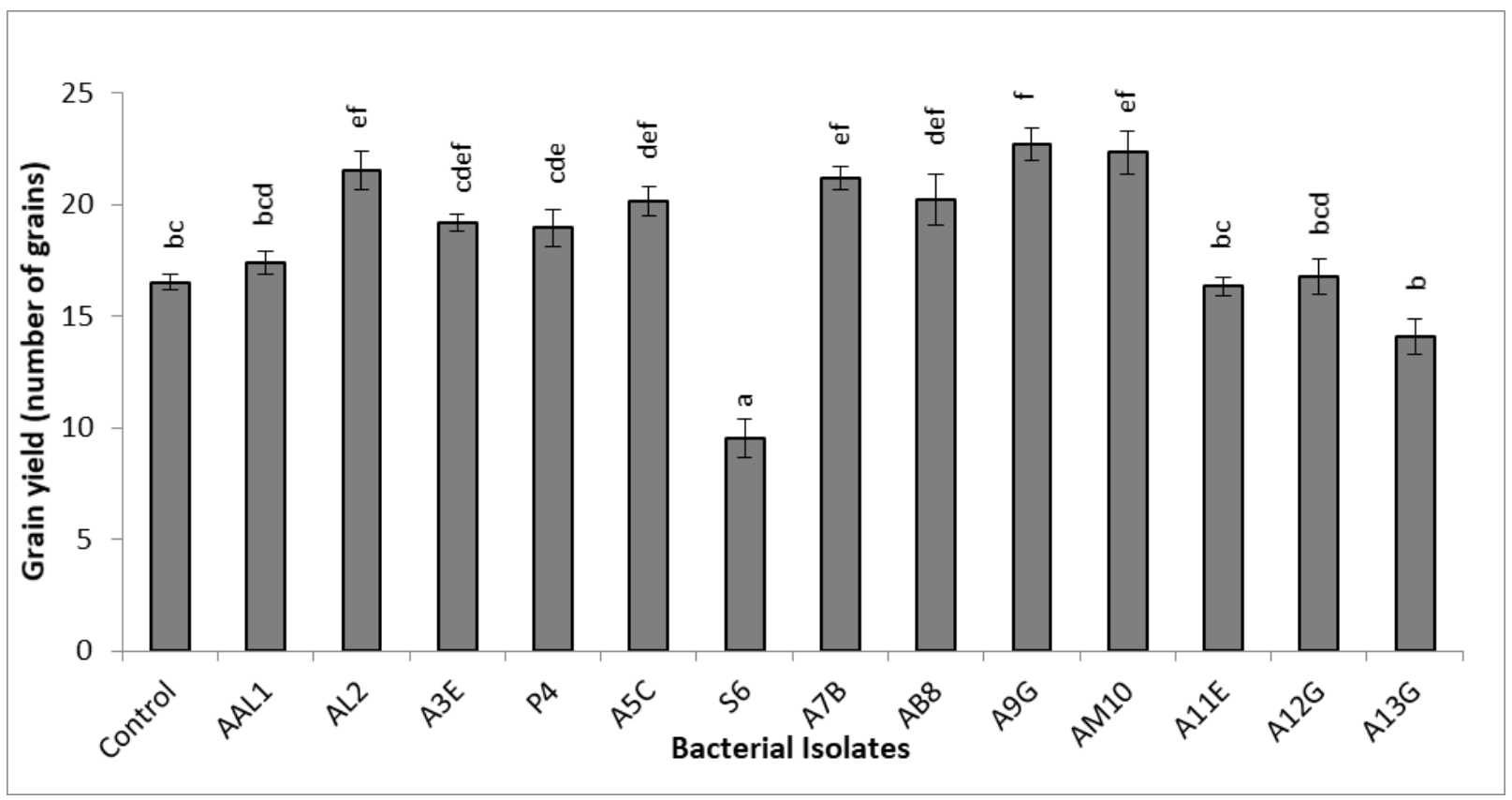

Fig. 6: Effect of bacterial inoculations on grain yield of Triticum aestivum ( $\mathrm{Fd}-08)$ under field conditions. Data represent mean of sixty-six plants. Different letters represent a significant difference between treatments using Duncan's multiple range test $(P=0.05)$. 


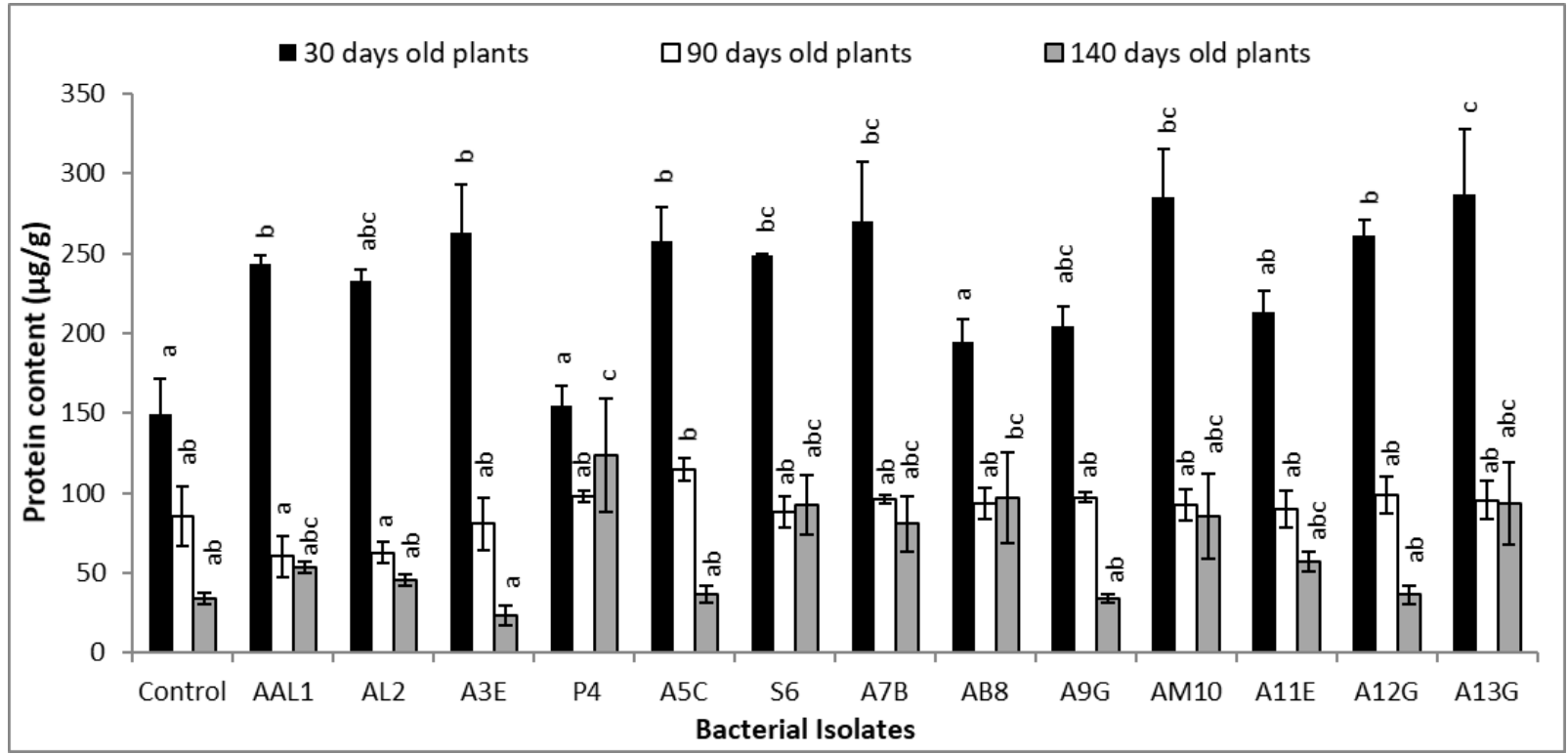

Fig. 7: Effect of bacterial inoculations on the protein content of 30,90 and 140 days old plants of Triticum aestivum (Fd08) under laboratory and field conditions. Data represent mean of sixty-six plants. Different letters represent a significant difference between treatments using Duncan's multiple range test $(P=0.05)$.

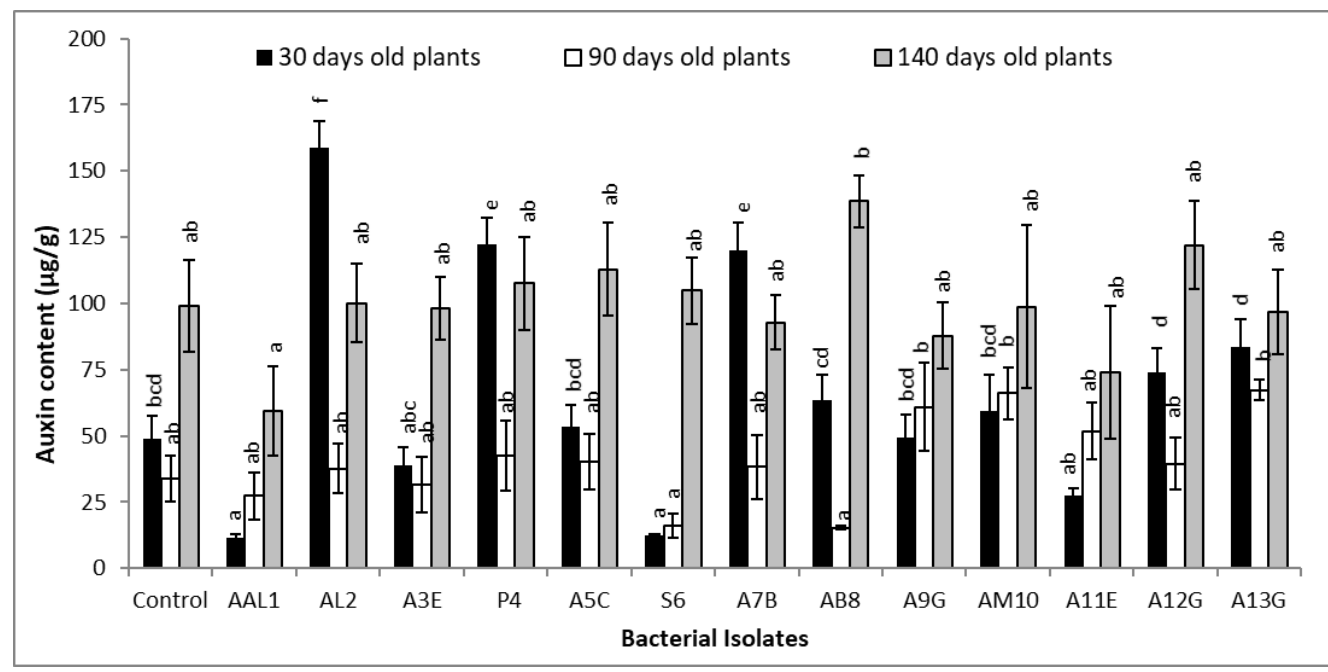

Fig. 8: Effect of bacterial inoculations on auxin content of 30,90 and 140 days old plants of Triticum aestivum (Fd-08) under laboratory and field conditions. Data represent mean of sixty-six plants. Different letters represent a significant difference between treatments using Duncan's multiple range test $(P=0.05)$.

While in 140 days old plants, maximum significant enhancement in protein content was shown in plants treated with Bacillus sp. (P4) up to $262 \%$ over control (Fig. 7). In 90 days old plants, $100 \%$ improvement in auxin content was observed in treatment with Exiguobacterium sp. (A13G) over non-treated plants. Auxin estimation of 140 days old treated and non-treated plants showed significant improvement in the quantity of auxin when treated with Bacillus sp. (AB8) i.e., 40\% over control (Fig. 8).

\section{DISCUSSION}

In the present world, the environmental issues relevant to increase in crop production are of great concern at the global level. Utilization of PGPR in this aspect is one of the most significant approaches in reducing the use of 
agrochemicals, balancing the ecosystem, maintaining soil, mobilizing nutrients and improving the crop quality ${ }^{7}$. Different mechanisms are involved in plant growth improvement like phosphate solubilization, nitrogen fixation, siderophore production, induced systemic resistance and antibiotic production, etc. ${ }^{12}$. Apart from these mechanisms, one major approach playing an essential part is the synthesis of phytohormones like gibberellins, auxins and cytokinins etc. ${ }^{13}$. In the class of naturally occurring auxins, the most essential plant growth regulator is IAA which is involved in a number of plant growth mechanisms like cell division, cell differentiation, metabolites production, germination of seed, development of root, pigment formation, adventitious roots initiation and photosynthesis ${ }^{14}$. Most of the PGPRs induce root developing system by maximizing the surface area, number, and size of root hairs ${ }^{15}$.

In the present work, FTIR analysis of microbial IAA obtained from the selected auxin-producing bacterial isolates i.e., S6, P4, A5C, A13G, A9G, A11E, AAL1, AB8, $A L 2, A 3 E, A 7 B, A 12 G$, and $A M 10$ was carried out. The interferograms obtained using bacterial IAA extracted from selected isolates (AB8, AAL1, A7B, A5C, A11E, A3E, A9G, AL2, P4, AM10, A12G, S6 and A13G) were compared with standard IAA verify the similarity between microbial IAA and synthetic IAA (Sigma). The interferogram obtained from standard IAA exhibited $-\mathrm{OH}$ band at $3384 \mathrm{~cm}^{-1}$. The region of $\mathrm{C}-\mathrm{H}$ stretching vibrations ranges between $2800-3100 \mathrm{~cm}^{-1}$ indicating the presence of amino acid and fatty acid. The $-\mathrm{CN}$ band lies near 737 $\mathrm{cm}^{-1}$ and the aromatic ring was in the range of 1405$1686 \mathrm{~cm}^{-1}$. Similar values were recorded for the $-\mathrm{CH}$ stretching band, $-\mathrm{OH}$ band, $-\mathrm{CN}$ band and an aromatic group of Enterobacter sp. (AM10) in comparison with the interferogram of standard IAA (Fig. 1). Comparable results were recorded with microbial IAA extracted from remaining bacterial isolates. The impact of their auxin production potential to modulate the growth of plants was further studied by application of these isolates on Triticum aestivum.

In the laboratory experiment, the plants treated with bacterial isolate Cronobacter sp. (AL2) showed maximum significant enhancement in germination percentage and shoot length i.e., 16 and $14 \%$ respectively, as compared to non-treated plants. From the selected bacterial isolates, maximum improvement in root length was shown by Enterobacter sp. (A7B) up to $27 \%$ over control (Fig. 2 \& 3). Plants inoculated with bacterial isolate Enterobacter sp. (A9G) exhibited significant improvement in the number of leaves i.e., $27 \%$ over non-treated plants. Plants inoculated with Bacillus sp. (S6) exhibited an increase in fresh weight i.e., $33.3 \%$ in comparison to plants without bacterial inoculation. However, few strains showed a reduction in the fresh weight of plants treated with bacterial isolates in comparison to non-treated plants (Fig. 4 \& 5). Under field conditions, plants treated with Enterobacter sp. (A5C) showed maximum increase in germination percentage up to $22.5 \%$ while the rest of the strains also showed moderate and slight improvement. Enterobacter sp. (A9G) showed an increase in shoot length up to $40 \%$ and significant improvement in leaves number was exhibited by Enterobacter sp. (A5C) up to $32 \%$ in comparison to control (Fig. $3 \& 4$ ). All the above results indicated that the auxin-producing isolates positively affected Triticum aestivum growth with significant improvements recorded in most of the growth parameters when compared with non-bacterial control treatments. PGPR have the ability of aggregating carbon compounds from the root hairs that can be used as an energy reservoir. They are involved in stimulating various growth factors such as inducing germination percentage, increasing root length and shoot length etc. by the synthesis of phytohormones which in turn stimulate the nutrients availability by mobilizing the nutrients absorption through enhancement of water uptake ability and minimizing the pathogenic attack on plants by accelerating the resistance mechanism and improving overall growth of plants ${ }^{9}$. Growth inducing mechanisms are more significant in roots overshoots. Auxins produced by the microbial strains have a remarkable effect on root growth especially in the initiation of roots, apical dominance, ethylene production, cell division and elongation ${ }^{16}$. Other researchers reported that the germination of tomato seeds by the application of bacterial inoculum showed enhancement in germination rate and root length over control ${ }^{13}$. Similarly, the seeds of chickpea treated with microbial strains showed improvement in shoot length up to $93 \%$ in comparison to control plants ${ }^{17}$. 
Under the field grown plants, improvement in various yield parameters was recorded as compared to control. Significant enhancement in spike length and spikelet length was recorded in plants treated with Enterobacter sp. (A5C) and Enterobacter sp. (A3E) upto18.1\% and $15.5 \%$ over control (Fig. 4 \& 5). Plants treated with Enterobacter sp. (A9G) exhibited maximum significant enhancement in tiller number up to $35 \%$ and grain yield up to $37.5 \%$ in comparison to non-inoculated plants while significant reduction in number of tillers and yield was observed in plants inoculated with Exiguobacterium sp. (A13G) and Bacillus sp. (S6) (Fig. 4 \& 6). Improvement in seed weight was recorded with Bacillus sp. (AAL1) and Enterobacter sp. (A5C) up to $29.7 \%$ and $27 \%$ respectively, over control (Fig. 5). The increase in spike length, spike number, spikelet length and tiller number might be due to reduced attack and sufficient availability of nutrients by applying plant health promoting rhizobacteria ${ }^{18,19}$. The increased photosynthetic activities and extensive uptake of nutrients and water resulted in better quality crops and increased yield ${ }^{20}$. Sufficient auxin content poses remarkable effect on plant yield and better development ${ }^{21}$. However, the amount of auxin supports plant growth up to a certain concentration. Any further increase in IAA above the limit would cause growth retardation especially in case of plant roots 22 . Enhancement of protein content was recorded in all the treated and non-treated plants at different stages of growth i.e., 30, 90 and 140 days old plants. However, minor difference was recorded in protein content at these three stages but out of all thirteen isolates, Enterobacter sp. (AM10) exhibited maximum significant increase in protein content in comparison to control up to $152 \%$ in 30 days old plants while in 90 days old treated plants, the bacterial isolates Enterobacter sp. (A5C) and Enterobacter sp. (AM10) exhibited maximum increase in protein content up to 34 and $8 \%$ respectively, over control. Thus, in 30 days old plants, treatment with Enterobacter sp. (AM10) showed maximum enhancement up to $152 \%$ but it was reduced to $8 \%$ in 90 days old plants since the proteins might have been utilized in photosynthesis and seed formation so a reduction in proteins was recorded with increasing maturity of plants. Protein analysis of 140 days old treated and non-treated fully grown plants exhibited significant improvement in protein content by treatment with Bacillus sp. (P4) up to $262 \%$ over control. At juvenile and middle stage of growth, proficient amount of soil nutrients were consumed by the plants attributed to protein synthesis in great amount. The increased protein synthesis leads to improved plant growth. However, in 140 days old plants, proteins were still produced but the quantity was decreased in comparison to the early growth phases (30 and 90 days old plants) (Fig. 7). PGPR is capable of fixing nutrients from the soil specifically nitrogen which maximizes the protein synthesis which in turn increases the crop yield. During seed development, a large amount of protein is utilized that causes a reduction in protein content at maturity 23,24 .

Estimation of auxin in 30,90 and 140 days old control and bacterially inoculated plants was also checked. Maximum improvement in auxin level was shown by the application of Cronobacter sp. (AL2) i.e., up to $224 \%$ in 30 days old treated plants over control while in 90days old plants inoculated with Exiguobacterium sp. (A13G), a significant increase in auxin content i.e., $100 \%$ over control was observed. Treatment with Bacillus sp. (AB8) exhibited $40 \%$ enhancement in auxin content in 140days old treated plants. Cronobacter sp. (AL2) showed maximum significant enhancement in auxin content in 30days old inoculated plants. But in 90days old AL2 treated plants, auxin content was reduced to $12 \%$ and in 140 days old treated plants, the auxin content recorded was up to $1 \%$ only (Fig. 8). This reveals that auxin is actively synthesized during early growth phases in the meristematic areas such as leaves then translocated to other plant regions which reinforce other mechanisms involved in the development of plants ${ }^{25}$. At premature phases of plant development i.e. 30 days old plants, the enhancement in auxin level could be attributed to the presence of meristematic areas in the shoot. Likewise, meristems of the root may also contribute to increasing the auxin content by enhancing the tryptophan availability i.e., a precursor for auxin synthesis. In 140 days old plants, wheat was fully grown and active meristematic points are not left in the plants. Another justification is that the microbial isolates vigorously synthesize auxin till juvenile stage so when the plants reached the mature stage, the microbes may not be actively responsive for 
auxin synthesis because there is a reduction in auxin level in mature plant regions.

Furthermore, some auxin-producing bacterial isolates may accelerate the growth of the plants at different phases. Some strains like Enterobacter sp. (AG9), Exiguobacterium sp. (A13G), Enterobacter sp. (AM10) have improved auxin content at mature stages of plant growth (Fig. 8). These bacterial isolates might not be very vigorously involved in auxin production during early phases of growth but become active at later growth stages and then synthesize greater amounts of auxin. Other elements involved in biochemical improvement still need to be studied further to comprehend the whole mechanism. Abbasi and his coworkers reported results similar to our findings that increase in auxin content of inoculated wheat seeds over non-inoculated seeds ${ }^{26}$. Vegetables treated by the application of bacterial strains manufacture auxin between 0.78-401.62 $\mu \mathrm{g} / \mathrm{ml}$ as compared to control 27.

\section{CONCLUSION}

Spectral analysis of the selected auxin-producing bacterial isolates (AB8, A7B, A5C, AAL1, A11E, A3E, A9G, AL2, P4, A12G, S6, AM10, and A13G) revealed that auxin produced by these bacterial isolates is structurally Indole-3-acetic acid (IAA). FTIR analysis further confirmed that microbial IAA is structurally similar to phytohormonal IAA thus exert beneficial impact similar to plant IAA e.g., increase the meristematic activity in plants which leads to improvement in plant growth and it is verified through in vivo studies using Triticum aestivum var. Fd-08. PGPR is indigenously present in nature so they are cost-effective and environment-friendly tools so their application as biofertilizer should be encouraged to improve plant growth and development. In addition, these are safer to practice, causing no deleterious effects on the ecosystem and living organisms around and exhibit considerable positive impact on crop quality and yield as demonstrated by the results recorded during the present study.

\section{REFERENCES}

1. Habig J, Hassen Al, Swart A. Application of microbiology in conservation agriculture. Conserv Agric. 2015 (doi: 10.1007/978-3-319-11620-4_20).

2. Deka H, Deka S, Baruah CK. Plant growth promoting rhizobacteria for value addition: mechanism of action.
Soil Biol. 2015; 42. (doi: 10.1007/978-3-319-134017_15).

3. Song X, Liu M, Wu D, Griffiths BS, Jiao J, Li H, et al. Interaction matters: Synergy between vermicompost and PGPR agents improves soil quality, crop quality and crop yield in the field. Appl Soil Ecol. 2015; 89: 25-34.

4. Vacheron J, Desbrosses G, Bouffaud M L, Touraine B, Moënne-Loccoz $Y$, Muller $D$, et al. Plant growthpromoting rhizobacteria and root system functioning. Front Plant Sci. 2013 (doi: 10.3389/fpls.2013.00356).

5. Nandal M, Hooda R. Plant growth promoting rhizobacteria: A review article. Int J Curr Res. 2013; 5(12): 3863-71.

6. Agrawal PK, Agrawal S, Kundan R, Bhatt M. Application and perspective of plant growth promoting rhizobacteria in development of sustainable agriculture. Int $\mathrm{J}$ Curr Res. 2014; 6 (10): 9044-51.

7. Chitraselvi PE, Kalidass S, Kant R. Efficiency of rhizosphere bacteria in the production of indole acetic acid, siderophore and phosphate solubilization. Int J Chem Tech Res. 2015; 7(6): 2557-64.

8. Gerhardt P, Murray RGE, Wood WA, Kreig NR. In: Methods for general and molecular bacteriology, 1994. American society for microbiology. Washington, D. C.

9. Ahmed A, Hasnain S. Auxin-producing Bacillus sp.: Auxin quantification and effect on the growth of Solanum tuberosum. Pure Appl Chem. 2010; 82(1): 313-9.

10. Lowry $\mathrm{OH}$, Resebrough NJ, Farr AL. Protein measurement with the folin-phenol reagent. J Biol Chem. 1951; 193: 265-75.

11. Mahadevan A. In: Growth regulators, Microorganisms, and diseased plants. 1984. Oxford and IBH Publishing Company, India, 31.

12. Prathap $M$, Ranjitha KBD. A critical review of plant growth promoting rhizobacteria. J Plant Pathol Microbiol. 2015 (doi:10.4172/2157-7471.1000266).

13. Mangmang JS, Deaker R, Rogers G. Effects of plant growth promoting Rhizobacteria on seed germination characteristics of tomato and lettuce. J Trop Crop Sci. 2014; 1(2): 35-40.

14. Ahirwar NK, Gupta G, Singh V, Rawlley RK, Ramana S. Influence on growth and fruit yield of tomato (Lycopersicon esculentum Mill.) plants by inoculation with Pseudomonas fluorescence (SS5): Possible role of plant growth promotion. Int $\mathrm{J}$ Curr Microbiol Appl Sci. 2015; 4(2): 720-30.

15. Jha CK, Saraf M. Plant growth promoting rhizobacteria (PGPR): A review. EJARD. 2015; 5(2): 0108-19.

16. Ahmed A. Efficacy of bacterial hormone in plant growth promotion. Ph.D. Thesis, 2011. The University of Punjab.

17. Dasgupta D, Ghati A, Sarkar A, Sengupta C. and Paul G. Application of plant growth promoting rhizobacteria (PGPR) isolated from the rhizosphere of Sesbania bispinosa on the Growth of Chickpea (Cicer arietinum L.). Int J Curr Microbiol Appl Sci. 2015; 4(5): 1033-42. 
18. Shirinzadeh A, Soleimanzadeh $H$, Shirinzadeh $Z$. Effect of seed priming with plant growth promoting rhizobacteria (PGPR) on agronomic traits and yield of Barley cultivars. World Appl Sci J. 2013; 21 (5): 727-31.

19. Haghighi $P$, Habibi D, Sani B. Wheat response to plant growth promoting rhizobacteria, humic acid and snbrassinolide. Int J Biosci. 2014; 5(10): 51-60.

20. Stefan M, Munteanu N, Stoleru V, Mihasan M, Hritcu L. Seed inoculation with plant growth promoting rhizobacteria enhances photosynthesis and yield of runner bean (Phaseolus coccineus L.). Sci Hort. 2013; 151: 22-9.

21. Aslantaş R, Çakmakçi $R$, Şahin F. Effect of plant growth promoting rhizobacteria on young apple tree growth and fruit yield under orchard conditions. Sci Hort. 2007; 111(4): 371-7.

22. Ahmed A, Hasnain S. Auxin as one of the factors of plant growth improvement by plant growth promoting Rhizobacteria. Pol J Microbiol 2014; 63(3): 261-6.
23. Fabre F, Planchon $C$. Nitrogen nutrition, yield and protein content in soybean. Plant Sci 2000; 152: 51-8.

24. Hassan A, Zamir MS, Khan I, Anjum SA, Mahmood A, Ahmed $A U H$, et al. Sustainable maize production through seed inoculation and different tillage regimes. Int J Agron Agric Res. 2014; 4(3): 67-76.

25. Tiberia I, Doru P, Catherine B. Auxin Control in the Formation of Adventitious Roots. Not Bot Horti Agrobio. 2011; 39(1): 307-16

26. Abbasi MK, Sharif S, Kazmi M, Sultan T, Aslam M. Isolation of plant growth promoting rhizobacteria from wheat rhizosphere and their effect on improving growth, yield and nutrient uptake of plants. Plant Biosys. 2011; 145(1): 159-68.

27. Dias A, Santos SGD, Vasconcelos VGD, Radl V, Xavier GR, Rumjanek NG, et al. Screening of plant growth promoting rhizobacteria for the development of vegetable crops inoculants. Afr J Microbiol Res. 2013; 7(19): 2087-92. 